CHAPTER VI

REPORT OF DIVISIONS, COMMISSIONS, AND WORKING GROUPS 


\section{DIVISION I}

\section{FUNDAMENTAL ASTRONOMY}

Division I provides a focus for astronomers studying a wide range of problems related to fundamental physical phenomena such as time, the intertial reference frame, positions and proper motions of celestial objects, and precise dynamical computation of the motions of bodies in stellar or planetary systems in the Universe.

PRESIDENT Nicole Capitaine

Observatoire de Paris

$D A N O F$

61 Av Observatoire

F 75014 Paris

France

Tel: $+33-140512231$

Fax:+33-1 40512291

Email:capitaine@obspm.fr

BOARD
J. Chapront
J.D. Hadjidemetriou
W. Jin
G. Petit
P.K. Seidelmann

President Commission 4

President Commission 7

President Commission 8

President Commission 31

Past President Division I

\section{PARTICIPATING COMMISSIONS}

COMMISSION 4: EPHEMERIDES

COMMISSION 7: CELESTIAL MECHANICS AND DYNAMICAL ASTRONOMY

COMMISSION 8: ASTROMETRY

COMMISSION 19: ROTATION OF THE EARTH

COMMISSION 31: TIME 
H. Rickman (ed.), Transactions of the International Astronomical Union, Vol. XXIVB, 85-85. (C)2001 IAU. Printed in the United States of America.

\title{
DIVISION I: FUNDAMENTAL ASTRONOMY
} (ASTRONOMIE FONDAMENTALE)

\section{PRESIDENT: P. Kenneth Seidelmann}

BOARD: E.M. Standish, C. Froeschlé, H. Schwan, D. McCarthy, E. Schilbach, T. Fukushima

Commission 4: Ephemerides

Commission 7: Celestial Mechanics and Dynamical Astronomy

Commission 8: Positional Astronomy

Commission 19: Rotation of the Earth

Commission 24: Photographic Astronomy

Commission 31: Time

The individual Commissions of Division I, namely Commissions 4, 7, 8, 19, 24, and 31 held business and scientific sessions at the General Assembly (See individual reports.) At this General Assembly the merger of Commissions 8 and 24 into a single Commission, 8 Astrometry, was completed.

The Working Groups of Division I presented reports and proposed resolutions at Joint Discussion 2, "Models and Constants for Submicroarcsecond Astrometry". These resolutions were adopted at the final General Assembly. The proceedings of the Joint Discussion can be found in Highlights of Astronomy, vol. 12 and the resolutions are in these Transactions.

The work of the division continues with the new president, Nicole Capitaine, the Commissions and the Working Groups which were established for the next triennium. The Working Groups are the Celestial Reference System, Relativity for Celestial Mechanics and Astrometry, Near Earth Objects (with Div. III), and Cartographic Coordinates and Rotational Elements of the Planets and Satellites (with Comm. 16 and IAG).

\author{
P. Kenneth Seidelmann \\ President of the Division
}


H. Rickman (ed.), Transactions of the International Astronomical Union, Vol. XXIVB, 87-90.

(C)2001 IAU. Printed in the United States of America.

\title{
COMMISSION 4: EPHEMERIDES
}

(EPHEMERIDES)

\author{
PRESIDENT: E. Myles Standish Jr. \\ VICE-PRESIDENT: J. Chapront \\ SECRETARY: C.Y. Hohenkerk \\ ORGANIZING COMMITTEE: V.K. Abalakin, J.-E. Arlot, T. Fukushima, \\ M.-F. He, G.H. Kaplan, H. Kinoshita, G.A. Krasinsky, J.H. Lieske, \\ H. Schwan, P.K. Seidelmann
}

Commission 4 held one business meeting, August 9, 2000.

Officers, 2000-2003 President: Jean Chapront; Vice-President: George A Krasinsky. Organizing Committee

$\begin{array}{lllll}\text { V K Abalakin } & \text { J-E Arlot } & \text { J Chapront } & \text { T Fukushima } & \text { C Y Hohenkerk } \\ \text { J H Lieske } & \text { G H Kaplan } & \text { H Kinoshita } & \text { G A Krasinsky } & \text { He Miao-Fu } \\ \text { H Schwan } & \text { P K Seidelmann } & \text { E M Standish } & & \end{array}$

New Members

John A Bangert, US Naval Observatory

Fu Yanning, Purple Mountain Observatory

Teodoro Lopez Moratalla, Real Inst y Obs de la Armada

Elena Pitjeva, Institute of Applied Astronomy

The Division I Chairs, P.K. Seidelmann (outgoing) and N. Capitaine (incoming) were welcomed. Apologies were received from Krasinsky, Schwan, and Moratalla.

Commission Website Standish commented that he saw that the job of the Commission was to create ephemerides and to make them available to the astronomical community and to the general public. Thus, a website (http://ssd.jpl.nasa.gov/iau-comm4) has been established, listing where to obtain various ephemerides, computer programs, and observational data, as well as related papers, meetings of interest, membership information, and links to related sites. Members are encouraged to contribute to this website.

\section{Reports from Various Institutions}

Astronomical Institute, Prague Vondrák reported that the Czech Republic has been, independently, producing an Astronomy Year Book since 1981, consisting of about 100 pages with a diskette. It contains all the standard information for $\mathrm{N}^{\circ} 0^{\circ} \mathrm{E} 15^{\circ}$ and is based on the VSOP82 ephemerides.

Bureau des Longitudes Arlot reported that since June 1998 the BdL had become part of the Institut de mécanique céleste et de calcul des éphémérides. All of their printed publications continue. They still run MINITEL to answer the questions from the public through the phone network. There is a developing web service for calculating positions and physical ephemerides. A web inter-connection to add solar system objects is in preparation. Data bases of natural planetary satellites, osculating elements for observable comets, and astrometric data of planets are being developed. The lattermost is managed with JPL. Most 
of the theoretical models, constants, and physical parameters are available via ftp. Other publications include Introduction aux éphémérides, Les éclipses du Soleil and Le calendrier républicain. Ephemerides continue to be developed; in particular, developing VSOP2000 which includes general relativity, and fitting observations of natural satellites to dynamical models.

Astronomisches Rechen-Institut Schwan, in a transmitted report, told that Apparent Places of Fundamental Stars (APFS) is now a small booklet with explanation and apparent places of 54 stars. The 2000 APFS booklet has been distributed with Timeindependent Auxiliary Tables, information that does not change with time. The latter will not be re-distributed each year. The web address of the full edition is www.ari.uniheidelberg.de/ariapfs. The main catalogue used is the Sixth Catalogue of Fundamental Stars, although the web also allows use of the Hipparcos catalogue. The web implementation also gives daily apparent places with and without inclusion of the short period nutation terms.

Jet Propulsion Laboratory Standish reported that planetary and lunar ephemeris work continues at JPL at a modest level. DE200 remains the standard ephemeris used in the world's almanacs; it covers the period, 1600-2169. DE405 and DE406 come from the same numerical integration which covered the interval, $3000 \mathrm{BC}$ to $3000 \mathrm{AD}$. They represent JPL's most recent ephemeris. DE405 is represented with full precision polynomials and covers $1600-2200$. DE406 covers the full integration period, $3000 \mathrm{BC}$ to 3000 $\mathrm{AD}$, but it is represented with less precise interpolating polynomials (maximum interpolating errors for DE406: $1 \mathrm{~m}$ for the moon; $25 \mathrm{~m}$ for the planets). These ephemerides are available on a CD-ROM obtainable from the publisher Willmann-Bell. The CD-ROM contains DE200, DE405, and DE406 in unix binary format, and DE200 and DE405 in ASCII format. Another CDROM, this one containing DE406 in ASCII format, is available (ems@smyles.jpl.nasa.gov).

JPL Solar System Dynamics Group maintains its own website, (http://ssd.jpl.nasa.gov) which includes the interactive ephemeris maker, "Horizons", that allows a user to create a custom-built ephemeris of any solar system body with a known orbit; the access is via www, telnet, or email.

US Naval Observatory Bangert reported that ephemeris activities at USNO are concentrated in the Astronomical Applications (AA) Department. Publication of The Astronomical Almanac (AsA), The Nautical Almanac, The (U.S.) Air Almanac, and Astronomical Phenomena continued as a joint activity between Her Majesty's Nautical Almanac Office (UK) and the U.S. Nautical Almanac Office. Revision of the AsA is in progress. Version 1.5 of the Multiyear Interactive Computer Almanac (MICA), covering years 1990-2005, was released in 1998. Version 2.0 of the Naval Observatory Vector Astrometry Subroutines (NOVAS), in both Fortran and C, was released in June 1999. USNO/AE98, a set of ephemerides for 15 large asteroids covering years 1800-2100, was released in June 1999. Determinations were made for the masses of 1 Ceres, 2 Pallas, and 4 Vesta. Newcomb, a new software system for generating modern fundamental ephemerides of major solar system bodies is under development. Further information on products and research, in addition to a variety of practical astronomical data, can be found on the AA Department web site (http://aa.usno.navy.mil/AA/).

National Astronomical Observatory, Japan Fukushima reported that their previous title was the Tokyo Observatory. They continue to produce the official Government Calendar, Almanacs and the Scientific Handbook. JPL's DE405 will not be used until the 2003 almanac which should be available in 2002 . However, at present, the Hydrographic Department still produces the more detailed almanacs. There is effort for pubic outreach via a public relations centre and a world wide web site receiving about 40,000 hits a month. 
Department of Fundamental Astronomy, Paris Observatory Chapront reported on the activities of the Lunar Analysis Centre (POLAC). Their general activities are the treatment and validation of LLR observations at CERGA and contributions to IERS/ILRS. Their main area of work is on Lunar theory and ephemerides and involves improvements of the orbital and rotational motion of the Moon and the fit to LLR observations. The improvements include the semi-analytical solution, ELP, with the new planetary perturbations on the Moon and librations, which complements the semi-analytical solution of $\mathrm{M}$. Moons. Fitting to LLR observations gives improvements to all relevant parameters. The main results for the past 2 years include the positioning of the inertial mean ecliptic of J2000.0 with respect to (1) mean Celestial Ephemeris Pole, (2) the International Celestial Reference System, (3) JPL numerical integrations DE200, DE403, DE405, and (4) correction to the IAU precession constant. Other activities involve the improvement of planetary theories over 6000 years on the basis of DE406, and the development of compact Poisson series ephemerides of Pluto. Collaborations with the astronomical community include providing positions and velocities of the Earth, planetary tables valid over 2000 years, solar eclipses, etc.

International Lunar Occultation Centre, Tokyo Sengoku reported that the Hydrographic Department of Japan took over the International Lunar Occultation Centre (ILOC) from the Royal Greenwich Observatory in 1981 in response to the request of Commission 4 of the IAU. Since 1981, 188,901 lunar occultation data have been reported to ILOC from 2343 stations, 8965 observers from 49 countries (as of 2000 June 28). Annually, about 10,000 lunar occultation data are reported from about 300 stations. Predictions of lunar occultations are mailed to about 300 observers every year. The reported data are analysed and sent back to the observers through the annual report of the ILOC, which is also available on line at (http://www.jhd.go.jp/cue/KOHO/iloc/obsrep/).

HM Nautical Almanac Office Bell reported that at the end of 1998, on the closure of the Royal Greenwich Observatory, the Office moved to the Rutherford Appleton Laboratory under the supervision of P.T. Wallace. Staff numbers were reduced by one third, but current publication schedules were maintained and, in the case of The Astronomical Almanac, in collaboration with USNO, brought forward.

Four new publications have been produced including the RGO Eclipse Guide, NavPac, Compact Data 2001-2005, and Planetary and Lunar Coordinates 2001-2020. HMNAO operates on a purely commercial basis and has to survive, without government support, on the sales of its publications; principally, The Nautical Almanac and data services. A memorandum of understanding between HMNAO and USNO has been signed allowing increased co-operation between both Nautical Almanac Offices.

Institute of Applied Astronomy, St Petersburg Pitjeva reported on the planetary and lunar ephemerides, EPM2000, which has been produced by a simultaneous numerical integration of the equations of motion of the nine major planets, the Sun, the Moon, lunar physical librations and 300 asteroids from 1886 - 2006. They were fit to over 80,000 observations, including American and Russian radar observations of the inner planets obtained from 1961-1997, Mariner-9 tracking data, Viking-1 and -2 lander data, Pathfinder ranging and differenced range, and all radio observations of Jupiter and spacecraft at Jupiter.

The values of all relevant astronomical constants were obtained in the fitting process. The rms of the post-fit residuals of the radar observations are $1.4 \mathrm{~km}$ for Mercury, $0.7 \mathrm{~km}$ for Venus and Mars; they are $8 m$ for the Viking landers and $4 m$ for the Pathfinder lander.

In conjunction with EPM2000 a numerical theory of the motion of the Moon has been developed by Aleshkina, Krasinsky and Vasilyev by fitting a 30-year set of lunar laser ranging data.

Laboratory for Ephemeris Astronomy (LAE) Yagudina reported on behalf of Krasinsky, chief of the Laboratory. The LAE has been constructing planetary and lunar ephemerides 
by processing ranging observations to the planets, the Moon, and the Galilean satellites, including optical observations of the Galilean satellites made in the Hipparcos system (ephemerides of the satellites are modeled by a numerical integration). Some inconsistency of the VLBI-based positions of Jupiter with the optical data have been noticed. This is possibly due to the dynamical theories of Jupiter and its satellites, and therefore some refinements are needed. Thus an approximate method to account for the effect of the Galilean satellite system upon the motion of the barycenter of the Jupiter system has been developed.

These investigations are carried out using ERA, the ephemeris and dynamical astronomy package for any celestial body (both natural and artificial), the manual of which is presented.

\section{Closing Remarks}

The meeting ended with a vote of thanks to Standish, the outgoing President.

E. Myles Standish

President of the Commission 
H. Rickman (ed.), Transactions of the International Astronomical Union, Vol. XXIVB, 91-93.

(C)2001 IAU. Printed in the United States of America.

\section{COMMISSION 7: CELESTIAL MECHANICS AND DYNAMICAL ASTRONOMY}

(MECANIQUE CELESTE ET ASTRONOMIE DYNAMIQUE)

\section{PRESIDENT: Claude Froeschlé \\ VICE-PRESIDENT: John Hadjidemetriou \\ SECRETARY: Anne Lemaître}

ORGANIZING COMMITTEE: R. Dvorak, S. Ferraz-Mello, T. Fukushima, I.A. Gerasimov, D.C. Heggie, Z. Knežević , J.H. Lieske, A. Milani, J.C. Muzzio, M. Soffel, Y.-S. Sun

Report of Meeting, 10 August 2000

\section{Election of the Organizing Committee}

The commission elected the following officers and members of the Organizing Committee for the term $2000-2003$ :

$\begin{array}{ll}\text { President: } & \text { J. Hadjidemetriou } \\ \text { Vice-President: } & \text { A. Milani } \\ \text { Secretary: } & \text { A. Lemaître } \\ \text { Members: } & \text { J. Burns } \\ & \text { R. Dvorak } \\ & \text { C. Froeschlé (Past President) } \\ & \text { T. Fukushima } \\ & \text { I. A. Gerasimov } \\ & \text { D. C. Heggie } \\ & \text { Z. Kneževíc } \\ & \text { J. C. Muzzio } \\ & \text { M. Sidlichovsky } \\ & \text { M. Soffel } \\ & \text { Y.-S. Sun }\end{array}$

\section{Election of Consultant Members of the Commission}

The following non-IAU members were elected as consultant members of Commission 7 for their extended contributions to activities relevant to the Commission :

\section{Re-elected}
A. Giorgilli (Italy)
K. R. Meyer (USA)
A. Neishtadt (Russia)
C. Simò (Spain)

\section{$\underline{\text { New consultants }}$}
A. Celletti (Italy)
B. Gladman (France)
M. Guzzo (Italy)

\section{Election of New Members of the Commission}

The following new IAU members were approved for membership in Commission 7, following proposals by their National Committees or by members of the Commission Organizing Committee: 


$\begin{array}{ll}\text { S. Breiter } & \text { Poland } \\ \text { J. Chambers } & \text { UK } \\ \text { P. Descamps } & \text { France } \\ \text { C. Giordano } & \text { Argentina } \\ \text { S. Giuliatti Winter } & \text { Brazil } \\ \text { P. Hallan } & \text { India } \\ \text { X. Hu } & \text { China PR } \\ \text { T. Kalvouridis } & \text { Greece } \\ \text { S. Klioner } & \text { Germany } \\ \text { E. Kuznetsov } & \text { Russia } \\ \text { A. Lecavalier des Etangs } & \text { France } \\ \text { S. Levine } & \text { USA } \\ \text { W. Liu } & \text { China PR } \\ \text { J. Ma } & \text { China PR } \\ \text { P. Michel } & \text { France } \\ \text { P. Patsis } & \text { Greece } \\ \text { Y. Xia } & \text { China PR } \\ \text { J. Xu } & \text { China PR } \\ \text { J.-L. Zhou } & \text { China PR }\end{array}$

The following IAU members (already members of another commission) were approved for membership in Commission 7, following proposals by members of the Commission Organizing Committee :
J. Burns
USA
J. Colin France
H. Varvoglis Greece

\section{Deceased Members}

At the session opening the presents revered the memory of those Commission members whose decease was brought to our knowledge:

$\begin{array}{ll}\text { Eichhorn, Heinrich } & \text { Kustaanheimo, Paul } \\ \text { Farinella, Paolo } & \text { Moons, Michèle } \\ \text { Garfinkel, Boris } & \text { Oesterwinter, Claus } \\ \text { Izvekov, Vladimir } & \text { Sessin, Wagner } \\ \text { Kaula, William } & \text { Szebehely, Victor }\end{array}$

\section{Web site of Commission 7}

The web site of the Commission has been updated; its address is http://www.elec.ucl.ac.be/IAU7/ which can also been reached through the IAU general web site. The members of Commission 7 would like to find on this site as many informations as possible about meetings or schools.

\section{Report of Activities 1987-2000}

The triennial report published in the IAU Transactions was written by specialists to review the progresses in some topics selected in advance.

For 1997-1999 the topics and the chosen specialists were :

- Dynamics of the Asteroid Belt : N. MURRAY

- Dynamical Transfer in the Solar System : B. GLADMAN

- Symplectic Integrators : J. E. CHAMBERS 
- Non-Integrable Galactic Dynamics : D. MERRITT

- Orbit Determination and Impact Risk : A. MILANI

\section{Future IAU Colloquia or Symposia}

Commission 7 tries to propose a Symposium every three years on a subject of actuality considered as relevant and broad enough to guarantee the support of a few other IAU Commissions.

For the past three years, no Symposium but two Colloquia were organized :

- IAU Colloquium 172 : Impact of modern dynamics in astronomy, Namur, Belgium, July 6-11, 1998

- IAU Colloquium 173 : Evolution and source regions of asteroids and comets, Tatranská Lomnica, Slovak Republic, August 24-28, 1998

The project for the next three years is to organize an IAU Symposium in Vienna, in September 2002.

\section{Celestial Mechanics and Dynamical Astronomy}

J. Henrard, editor in chief of Celestial Mechanics and Dynamical Astronomy presented a report on the current situation of the journal.

Of the two main problems for the Journal mentioned in the report three years ago (Science citation index and delays of publication), one has been solved and the other one is on its way to being solved. The Journal is again in the list of "source journals" for the Science citation index with an impact factor of 0.445 , which is not bad for a mathematical journal and not very good for an astronomical journal. Let us recall that actually the impact factor does not measure the real impact of a journal but its immediate impact, as only citations of papers published in the last two years are counted. For fields where the speed of publication is lower this is much too short.

The second problem concerned the fact that the Journal was late by about six months with respect to the announced schedule of publication. The Journal is still late by a few months but the gap will close probably in 2001 because the flow of submissions is now large enough.

\section{Commission meetings during the General Assembly}

The following question was debated in Manchester, in the meeting of the presidents of Commissions : should the meetings of the Commissions during the General Assembly be only business, or should they include scientific matters? No general decision was taken in Manchester. The problem is that these meetings are not attended by many people, especially not by young scientists. An interesting Commission meeting could attract the attention of more people, to attend the General Assembly. It was also mentioned that many people would be reluctant to present scientific papers in a Commission meeting if there will not be any proceedings to publish their work.

For Commission 7, a first proposal would be to present only review papers, focusing on the current topics of research in Celestial Mechanics and Dynamical Astronomy, together with information on where such research is taking place. The SOC has to think about this proposition for Sydney 2003. 
COMMISSION 8: POSITIONAL ASTRONOMY (ASTRONOMIE DE POSITION)

COMMISSION 24: PHOTOGRAPHIC ASTROMETRY (ASTROMETRIE PHOTOGRAPHIQUE)

\author{
PRESIDENT, COMMISSION 8: Heiner Schwan \\ PRESIDENT, COMMISSION 24: Elena Schilbach \\ VICE-PRESIDENT, COMMISSIONS 8 and 24: Wen-Jing Jin \\ ORGANIZING COMMITTEES: \\ COMMISSION 8: T.E. Corbin, J. Kovalevsky, J.A. Lopez, L.V. Morrison, \\ F. Noel, G. Pinigin, D. Polojentsev, R. Stone, J. Xu \\ COMMISSION 24: M. Crézé, P.D. Hemenway, I.I. Kumkova, I.K. Platais, \\ S. Roeser, C. Turon, Wang Jia-Ji
}

\title{
1. Commission 8: Business session 9 August, 2000
}

The President presented the agenda for the business meeting which was approved by members. A major effort in the past triennium was the final merging of Commission 8 and Commission 24, including the creation of a new membership file and the establishment of a new Scientific Organizing Committee (SOC) according to the decisions adopted at the last General Assembly (GA) in Kyoto (1997). Most of these tasks were made in close contact with Commission 24. The concordant collaboration with Dr. Elena Schilbach, President of Commission 24, is thankfully recognized. Special thanks were also expressed to the members of the SOC and to Dr. Ken Seidelmann, President of Division I, for their permanent advice and assistance.

\section{IN MEMORIAM}

A moment of silence was observed by the Commission members noting the deaths of the following colleagues: C.A. Anguita, B.K. Bagildinsky, H.K. Eichhorn.

\section{MERGER WITH COMMISSION 24}

The merger of Commission 8 and Commission 24 was decided at the GA in Kyoto with overwhelming majority (see Trans. of the IAU, Vol. 23B, p.85ff, 1999). One of the steps to be undertaken was the creation of a new membership file: A questionnaire was sent by e-mail to all members of Commission 8. Members who did not answer by e-mail received the questionnaire by regular mail. The response was as follows: 
answers received: 130 ( 100 by e-mail, 30 by regular mail) answers indicating resignation: 11

no answer: 57

Altogether 119 members of the "former" Commission 8 will thus become members of the merged commission. More information is given in the report on the joint meeting.

\section{REPORTS ON ASTRONOMY}

A full report presenting the main scientific activities during the past triennium 1996 through 1999 was published in Trans. of the IAU, Vol. $24 \mathrm{~A}, 2000$ and made available additionally via the Internet.

\section{SPONSORSHIP OF IAU SYMPOSIA AND COLLOQUIA}

- Symposium 200:

The Formation of Binary Stars, Potsdam, Germany, April 2000

- Colloquium 180:

Towards Models and Constants for Sub-microarcsecond Astrometry,

Washington DC, March 2000

\section{Commission 24: Business session 9 August, 2000}

During the triennium 1997-2000, a major effort was undertaken to put into practice the merger with Commission 8 decided at the last GA in Kyoto. This process included the establishment of the new Commission's membership and the election of the SOC and VicePresident.

Close cooperation and coordination with Dr. H. Schwan, President of Commission 8 , was one of the important preconditions for a success. Special thanks must also go to the SOC of Commission 24 and to Dr. Ken Seidelmann, President of Division I, for their permanent assistance.

\section{IN MEMORIAM}

A minute of silence was observed in memory of the members who left us during the last triennium: Heinrich K. Eichhorn, Luiz da Silva Machado, Charles Worley.

\section{MERGER WITH COMMISSION 8}

According to the "merger procedure" proposed at the GA in Kyoto, the members of the Commission had to be polled by the President. Only those requesting membership in the new Commission became members. The intention was to terminate the membership of colleagues who no longer have research interests in astrometry.

A questionnaire was sent by to all members of Commission 24 by e-mail. Members who did not answer received the questionnaire by regular mail. This procedure helped to update the address and electronic address lists. The response was as follows:

answers received: 
101 ( 92 by e-mail, 9 by regular mail)

answers indicating resignation: 10

no answer: 27

Thus, altogether 91 members of the "former" Commission 24 asked for membership in the merged Commission.

\section{REPORTS ON ASTRONOMY}

Main activities of the Commission members in the field of Astrometry were overviewed in the Report of Commission 24. The report covering scientific contributions within the triennium 1996-1999 was published in Trans. of the IAU, Vol. 24A, 2000.

\section{SPONSORSHIP OF IAU SYMPOSIA AND COLLOQUIA}

- Symposium 200:

The Formation of Binary Stars, Potsdam, Germany, April 2000

- Colloquium 180:

Towards Models and Constants for Sub-microarcsecond Astrometry, Washington DC, March 2000

\section{Joint Session of Commissions 8 and 24: 14 August 2000}

\section{MERGER OF COMMISSIONS 8 AND 24}

Name and number of the new Commission: According to the decisions made at the General Assembly in Kyoto, Japan (see Trans. of the IAU, Vol. 23B, p.85ff, 1999) Commission 8 (Positional Astronomy) and Commission 24 (Photographic Astrometry) merged at the XXIVth General Assembly in Manchester. The new Commission is referred to as Commission 8 with the title "Astrometry".

Officers for the next triennium 2000-2003: At the GA in Kyoto Wen-Jing Jin (Shanghai Observatory) was approved as Vice-President of both Commissions 8 and 24 for the triennium 1997-2000. At the GA in Manchester Wen-Jing Jin became President of the new Commission.

The new Vice-President was elected by the members of the Scientific Organizing Committees of both Commissions. From 15 valid votes, 8 were in favour of Imants Platais (US Naval Observatory, Washington DC), 7 votes were distributed among 3 other candidates.

The SOC of the new Commission was formed on the basis of SOCs of Commission 8 and Commission 24, and by including new SOC members and taking into account a geographical aspect. The proposal approved by a ballot organized by e-mail among the combined membership was confirmed at the business meeting: 
President:

Vice-President:

Organizing Committee:
Wen-Jing Jin (Shanghai Observatory, China)

Imants Platais (US Naval Observatory, USA)

Edgardo Costa (Chile), Christine Ducourant (France), Irina Kumkova (Russia), Mario Lattanzi (Italy), Chunlin Lu (China), Siegfried Roeser (Germany), Elena Schilbach (Germany), Heiner Schwan (Germany), Ronald Stone (USA)

Their e-mail addresses are given below:

\begin{tabular}{ll}
\hline Wen-Jing Jin & jwj@center.shao.ac.cn \\
Imants Platais & imants@usno.navy.mil \\
Edgardo Costa & ecosta@das.uchile.cl \\
Christine Ducourant & ducourant@observ.u-bordeaux.fr \\
Irina Kumkova & kumkova@quasar.ipa.nw.ru \\
Mario Lattanzi & lattanzi@to.astro.it \\
Chunlin Lu & cllu@pmo.ac.cn \\
Siegfried Roeser & s19@ix.urz.uni-heidelberg.de \\
Elena Schilbach & eschilbach@aip.de \\
Heiner Schwan & schwan@ari.uni-heidelberg.de \\
Ronald Stone & rcf@nofs.navy.mil \\
\hline
\end{tabular}

New membership list: During the first quarter 2000, the Presidents sent a questionnaire by e-mail and/or mail to all members of the former Commissions 8 and 24 asking whether they were requesting membership in the new Commission. This opportunity was also taken to update addresses and, in particular, the e-mail addresses of the new Commission members. The responses received are the following:

Number of members of the "old" Commission 8

Number of members of the "old" Commission $24 \quad 128$

Number of members resigning or not answering 104

Number of new members (neither in Comm. 8 nor in 24 before) 26

Final number of members of the new Commission $8 \quad \underline{212}$

The following new members were approved, under the reservation that they were already or would become IAU members: 
a) IAU members requesting new Commission membership

Chen, Li

Evans, Dafydd Wyn

Gaume, Ralph

Gouda, Naoteru

Mioc, Vasile

Morbidelli, Roberto

Pannunzio, Renato

Pauwels, Thierry

Popescu, Petre

Santamaria, Raffaele

Seidelmann, Ken

Tsujimoto, Takuji

Vass, Gheorghe

Wang, Zhengming
Shanghai Observatory

Institute of Astronomy, Cambridge

US Naval Observatory, Washington

National Astronomical Observatory, Tokyo

Astron. Inst. Romanian Academy, Bucarest

Oss. Astr. Torino

Oss. Astr. Torino

Koninklijke Sterrewacht van Belgie

Astron. Inst. Romanian Academy, Bucarest

Institute of Navigation, Napoli

US Naval Observatory, Washington

National Astronomical Observatory, Tokyo

Astron. Inst. Romanian Academy, Bucarest

Shaanxi Astronomical Observatory
China

UK

USA

Japan

Rumania

Italy

Italy

Belgium

Rumania

Italy

USA

Japan

Rumania

China

b) New IAU members requesting new Commission membership

Andrei, Alexandre Humberto

Bakhtigaraev, Nail

Belizon, Fernando

Germain, Marvin E.

Hajian, Arsen R.

Kuimov, Konstantin

Lazorenko, Peter F.

Ma, Whenzhang

Shokin, Yurij A.

Sovers, Ojars

Vertypolokh, Olexander Y.

Yatsenko, Anatoly I.
Obs. Nacional, Rio de Janeiro

Institute of Astronomy, Moscow

Real Inst. y Obs., La Armada, S. Fernando

US Naval Observatory, Washington

U.S. Naval Observatory, Washington

Sternberg Astr. Inst., Moscow

Main Astr. Obs., Golosiiv, Kyiv

Beijing Normal University

Sternberg Astr. Inst., Moscow

Remote Sensing Analysis Systems, Altadena

Astronomical Observatory, Kyiv

Main Astr. Obs., Goloseevo, Kyiv
Brasilia

Russia

Spain

USA

USA

Russia

Ukraine

China PR

Russia

USA

Ukraine

Ukraine

\section{Report of the Working Groups: Joint session 14 August 2000}

\section{ASTROGRAPHIC CATALOGUE PLATES}

Membership list : A. Fresneau (Chair), C. Abad, F. Arias, O. Bienaymé, J. Biggs, N. Brosch, P. Brosche, B. Bucciarelli, T. Corbin, G. Coyne, E. Davoust, W. Dick, J. Dommanget, C. Ducourant, T. L. Evans, I. B. Fierro, M. Geffert, E. Glushkova, J. Guibert, M. Hiesgen, M. Irwin, D. Jones, K. Kuimov, A. Kuzmin, F. van Leeuwen, C. Li, K. Lumme, D. Monet, M. Odenkirchen, R. Orellana, A. Ortiz-Gil, T. Pauwels, T. Rafferty, M. Sanchez, J. Sanner, R.-D. Scholz, C. Soubiran, J. Stock, M. Tsvetkov, S. Urban, A. Vaughan, C. de Vegt, G. White.

General report on the AC project (A. Fresneau, Observatoire de Strasbourg) The Astrographic Program has provided 10000 deep plates down to an apparent blue magnitude of $14.5 \pm 1.5$ at the mean epoch $1912 \pm 20$. These plates, which cover the complete sky, have a magnitude limit about 3 mag fainter than for the presently available $A C$ catalogue. The exposure time was about $90 \mathrm{~min}$ per plate and the measuring time for one plate with a modern machine is on the order of $30 \mathrm{~min}$. A triple exposure technique was applied to segregate stars from plate defects and to estimate possible short-term variabilities of about 0.4 magnitude within the complete exposure time. A combination of these old observations which can now be reduced with the TYCHO II catalogue could yield a proper motion accuracy at a level of $2-3 \mathrm{mas} / \mathrm{yr}$. 
A set of about 100 plates was scanned with different machines whose repeatability is known to be of the order of 1 micrometer. From the comparison of triple exposures, an internal accuracy of about 2-3 microns and 0.15 mag has been achieved. However, an external accuracy of 5-6 micrometers and $0.35 \mathrm{mag}$ was estimated from a comparison with independent catalogues. With a plate scale of 0.06 arcsec per micrometer, this corresponds to 0.3 arcsec, a rather low accuracy compared to modern transit observations. A significant increase of astrometric accuracy to 0.06 arcsec is possible provided that a sophisticated plate reduction supported by the PSF modelling over a normal astrograph field of view of $2 \times 2$ square degrees will be applied. Scientific programs underway include measurements of the Cape zone with the STARSCAN (Washington D.C.) and the Bordeaux and Sydney zones with the APM (Cambridge).

The importance of a new project, UDAPAC (see below), proposed by the Brussels observatory to archive and digitize photographic observations has been recognized and supported by the Working Group.

Report on the accuracy inherent in the $A C$ and $C d C$ plates (S. Urban, USNO) S. Urban reported on the accuracy inherent in the Astrographic Catalogue and Carte du Ciel plates, and how this accuracy should dictate re-measurement efforts. The lens design of each telescope used (with one exception) produced a scale of $60 \mathrm{arcsec} / \mathrm{mm}$, or $60 \mathrm{mas} / \mathrm{micron}$. The plates suffer from guiding effects, and a combination of optical aberrations like curved focal plane, coma, color magnification error, and astigmatism. However, the $2 \times 2$ degree field of view is fairly small, so these effects are not disastrous. From data recently attained by L. Winter utilizing the USNO "Starscan" measuring machine and a deep Cape CdC plate, it is estimated that the positional information contained on the plates is in the 1 to 2 micron range. So as to not substantially increase the resulting positional accuracies, measuring machines with sub-micron precision should be employed in any type of measurement program.

Report on the Bordeaux Meridian 2000 project (C. Ducourant, Observatoire de Bordeaux) In 1997 the re-observation of the Bordeaux Carte du Ciel zone with the automated CCD meridian instrument operating in drift scanning mode was started at Bordeaux. The main scientific objectives are to extend the HIPPARCOS reference system down to $V=16$ and to derive proper motions for all stars on the Carte du Ciel plates $(V \leq 14)$ in this zone. Specific scientific "by-products" such as variable stars, high proper motion stars or PMS stars have been also associated with this project.

Meridian observations over about four years are nearly finished. Each measured object was observed at least 6 times yielding an astrometric precision of $\sigma=40$ mas for $V<14$, of $\sigma=80$ mas for $14<V<15$, and of $\sigma<130$ mas for $V<16$.

About 400 Carte du Ciel plates are scanned and analysed with the Cambridge APM (B. Argyle) yielding positions and fluxes for the detected stars. Further analysis based on software developed at Bordeaux will identify triplets and doublets, and eliminate the reseau measurements. The final global reduction of the 3 exposures with the TYCHO II catalogue will provide positions and photographic magnitude for all measured objects. A positional accuracy better than 0.2 arcsec is expected from preliminary tests. Combining these early epoch positions with the meridian observations mentioned before (and additionally including other available catalog positions such as AC2000, USNO A2.0, TAC) will provide proper motions with an accuracy of about 2 mas/yr for objects brighter than $V=14$.

Report on the Present Status of the Greenwich, Oxford and Cape AC Plates (D. Jones, Institute of Astronomy, Cambridge, Great Britain) The astrographic catalogue is mostly based on exposures of $6 \mathrm{~min}, 3 \mathrm{~min}$ and $20 \mathrm{sec}$. The Carte du Ciel plates are based either on three 20 minute exposures in the form of an equilateral triangle or on a single exposure 
of $60 \mathrm{~min}$.

The Greenwich Plates comprise (1) The 1900 catalogue plates, both 3 min and 6 min measured (2) The 1900 chart plates, with single not triple exposures (3) The 1925 proper motion plates, through the glass, only significant proper motions measured, and (4) The 1965 series from Herstmonceux, not complete, mostly 6 minutes, through the glass and without a reseau.

The Oxford plates comprise (1) The 1900 Catalogue plates (2) The 1930 Oxford II plates of the Potsdam zone, and (3) The 1965 series from Herstmonceux, not complete, mostly 6 minutes, through the glass and without a reseau.

Following the closure of the Royal Greenwich Observatory all these plates are held by the Particle Physics and Astronomy Research Council (PPARC). If properly conserved, the plates should outlast both paper and computer media. Whilst a permanent home is sought, PPARC have stored the Greenwich and Oxford plates, along with many other collections, in a climate-controlled repository in London. Access to the plates is possible, but each case is assessed on the ease of provision and cost. Applications to use the plates for scientific study should be addressed to Mr. Andy Thompson (Andy.Thompson@pparc.ac.uk Tel: +4401793 442101).

The Cape Plates comprise four series: The first series were exposed 1892-96 with exposures of $6 \mathrm{~min}, 3 \mathrm{~min}$ and 20 seconds. Each has a reseau superposed and the limiting magnitude is 12 . All series contain 1512 plates. The second series were exposed in the same way as the first in the years 1897-1910 and are known as the "new" series. These plates form the basis of the Astrographic Catalogue and all the plate details can be found there. The limiting magnitude is 12.7. The third series are the "1925" series which form the basis of the "Proper Motions of 20,843 Stars"(Spencer Jones and Jackson, 1936). These plates were exposed through the glass with exposures of 18,6,2 mins and 40 seconds and the limiting magnitude is 14.5. There is no reseau. The fourth series is the chart series which have a single exposure of unknown length (30 mins?). Each exposure has a reseau. The limiting magnitude is $\mathbf{1 5}$. These plates were exposed with three images for the odd degrees of declination and one image for the even degrees.

Generally speaking the images are of a uniform quality throughout, round in the middle of the plate and elongated in the corners. The quality of processing and preservation generally improves with time; probably most plates exposed post 1897 remain measurable. The number of plates mislaid or out on loan appears to be minimal. The contact person in Cape Town is presently Dr. T. Lloyd Evans but from 2001 March will be Dr. J. A. R. Caldwell.

Vote on the continuation of the Working Group After the discussion of the presented reports, members voted on the continuation of the working group. The membership was in favour of continuation except for one abstention.

Information by E. Griffin (Oxford) on Plate Archives: A new digitizing project, UDAPAC (the Uccle Direct Astronomical Plate Archive Centre), has been launched at the Royal Observatory of Belgium. Its 5-year remit is to collect, catalogue and preserve the inactive collections of direct plates currently stored in Europe, and to carry out a programme of digitization. The tasks necessary to achieve the objectives are being shared among its Support Group (initially 16 scientists from 9 countries) and consultants. The scanning will be accomplished selectively through a variety of techniques and instruments, according to the perceived quality and potential of the observations. The project will involve storage refurbishment, hardware installation, pilot research projects, a digital interface with global access, and the preservation of historic material, and funding will be sought for each stage. UDAPAC is now an exemplar for an international concern over the preservation of all photographic archives (see IAU Resolution B3, 2000).

The project will address astrometry as well as photometry, so Commission 8 is an obvious anchor-point for the initiative. With one objection and one abstention, the membership 
supported the project addressed by E. Griffin.

\section{ASTROLABES}

Final report (A. Andrei, Observatorio Nacional, Rio de Janeiro) Danjon astrolabes at CERGA in France, at San Fernando in Spain, at Sao Paulo and Rio in Brazil are now equipped with CCD video cameras to measure the solar diameter and its variations over time. However, that kind of observation are mostly under the auspices of Commission 12 and Division II.

Other astrolabes are still working on star catalogues. The importance of such work has greatly diminished since the appearance of the Hipparcos and Tycho catalogues. Instrumental upgrades such as a modified optical system instead of Wollaston prism, the use of CCDs as detectors etc. have been carried out at the Poznan and Bucharest observatories. It is expected that observations with these modified instruments can provide accurate positions of faint stars, variables, minor planets, and comets.

Recommendations Despite this progress, it was felt that the WG on Astrolabes has completed its mission and, hence, has been disbanded. The importance of the Solar observations has been recognized by the attending members and the continuation was recommended with four objections and no abstention. It was recommended to contact relevant groups of Commission 12 in order to optimize the observing programs.

The establishment of a proposed WG on Alt Azimuth CCD Astrometry was rejected because their goals could easily be included in the WG on Future Developments in Ground Based Astrometry (see next Section).

\section{FUTURE DEVELOPMENTS IN GROUND BASED ASTROMETRY}

Discussions on the future use of the classical astrometric instruments such as meridian circles, transit instruments or astrolabes had been started in October 1999 by e-mail, initiated by Magda Stavinschi, Bucharest Observatory, Rumania. M. Stavinschi proposed to establish a working group responsible for the future use of these instruments. The preliminary result of the e-mail discussion was rather controversy, from strong support to complete rejection.

It was recognized by the members attending this joint business meeting, that the postHipparcos era has brought an element of uncertainty as to the goals and future programs for all of ground-based astrometry. It was also recognized that there exists a number of ground based instruments, in particular in the developing countries, which could still contribute scientifically valuable observations in special fields of research. In order to identify such programs and make assessment of the whole situation including available instrumentation, draft proposals for a new WG on "The Future Developments of Ground-Based Astrometry" were made by J. Kovalevsky and K. Seidelmann. A vote was taken on the final version of the proposal, which resulted from discussions within the membership. The establishment of the proposed working group and the wording of the proposal given below was accepted unanimously. N. Capitaine, the new President of Division I, submitted the following proposal to the Executive Committee of the International Astronomical Union:

WG ON FUTURE DEVELOPMENTS IN GROUND BASED ASTROMETRY

(Chairperson: Magda Stavinschi, Co-Chairperson: Jean Kovalevsky)

\section{Objective}

- to identify scientifically important programs that can be realized using ground based astrometric or related observations. 
- to study what modifications, upgrading or addition to existing instruments should be performed in order to provide useful astronomical information with necessary accuracies keeping in mind what future satellites will contribute.

\section{Procedure}

1. Identify scientific purposes.

2. Identify astrometric observations required for scientific purposes.

3. Identify theoretical developments required for scientific purposes.

4. Propose astrometric observations and identify instruments available for new programs.

5. Propose new instruments required.

6. Identify astrometric programs to fulfill scientific programs.

Goals for triennium $2000-2003$

1. Accomplish $1-6$ above

2. Seek to promote and develop funding for viable scientific programs.

3. Seek redirection for situations that cannot support viable scientific programs.

\section{Individual Reports: Joint session 14 August 2000}

DIVA (Röser, ARI Heidelberg) DIVA is a small astronomy satellite proposed within the scientific programme of the German Space Agency (DLR). It will measure positions, proper motions and parallaxes, magnitudes and colors of about 35 million stars down to $V=15$ and obtain low resolution spectrophotometry for stars down to $\mathrm{V}=13.5$. DIVA will perform a survey of the whole sky only limited by the sensitivity of its instruments. It will surpass the performance of ESA's Hipparcos in all relevant aspects: by the number of objects observed, the measurement accuracy and by its vast number of photometric and spectrophotometric data. Project studies performed in the period 1997-2000 have proven the technical feasibility of the DIVA mission. With a launch in 2004,2 years of operations, followed by 2 years of data reduction, results are planned to be published by 2008. A decision on the next DLR mission is expected before October 2000. (During the preparation of this report, October 2000, DLR announced the selection results approving DIVA as Germany's next small space science mission with launch in 2004).

FAME (Urban, U.S. Naval Observatory) S. Urban presented a status report on the FAME astrometric satellite. He described the present schedule; Phase A was completed in September 1999, but Phase B is not scheduled to start until September 2000. The one year interim is due to the launch being scheduled for June 2004 instead of one year earlier, as was originally proposed. During the time between Phases A and B, the FAME team has been working aggressively on specifying the requirements for the CCDs and soliciting bids from different vendors. In late July, SITE Corporation was awarded the contract to provide 44 science grade and 10 engineering grade $2 \mathrm{k} \times 4 \mathrm{k} C \mathrm{CDs}$, each having 15 micrometer pixel size. Delivery is scheduled for December 2001. In addition to the CCD procurement, the FAME team has been working on the spacecraft and instrumentation requirements, the data simulator, and the data pipeline with emphasis on point-spread function fitting.

GAIA (Lindegren, Lund Observatory) GAIA is a candidate for the 5th Cornerstone of the European Space Agency's science programme, with possible launch in 2009 . The main science goals are the formation and evolution of our Galaxy, kinematics and dynamics of the Galaxy, and the physics and evolution of stars and planets. All pointlike objects brighter than $20 \mathrm{mag}$ are observed, with astrometric accuracies around 10 microarcsec at $15 \mathrm{mag}$. Multiband photometry are obtained for all sources, and radial velocities (to a few $\mathrm{km} / \mathrm{s}$ ) 
for those brighter than 17 mag. During 1997-1999 a comprehensive project study was conducted, lead by ESA, space industry and the GAIA Science Advisory Group: M.A.C. Perryman (chair, study scientist), O. Pace (study manager), K.S. de Boer, G. Gilmore, E. Høeg, M.G. Lattanzi, L. Lindegren, X. Luri, F. Mignard and P.T. de Zeeuw. A study report (380 pp) and executive summary (75 pp) have been published (ESA-SCI(2000)4). Conclusions of the study are that the mission is technically feasible, within the cornerstone cost envelope, and with an extremely strong science case. A decision on the future ESA science programme is expected after presentation of the various mission studies in Paris, September 2000. (During the preparation of this report, October 2000, ESA announced the selection of GAIA as the 6th Cornerstone to be launched no later than 2012).

TYCHO2 (Høg, Copenhagen University Observatory) The Tycho-2 Catalogue by Høg et al. (A\&A 355, L27, 2000) is an astrometric reference catalogue containing positions and proper motions as well as two-colour photometric data for the 2.5 million brightest stars in the sky. The catalogue is distributed on CD-ROM and through the astronomical data centres, and further information is given on the website

http://www . astro.ku.dk/ erik/Tycho-2.

The Tycho-2 positions and magnitudes are based on precisely the same observations as the original Tycho Catalogue (hereafter Tycho-1) collected by the star mapper of the ESA Hipparcos satellite, but Tycho-2 is much bigger and slightly more precise, owing to a more advanced reduction technique described by $\mathrm{H} ø \mathrm{~g}$ et al. (A\&A 357, 367, 2000). Components of double stars with separations down to 0.8 arcsec are included. Proper motions precise to about $2.5 \mathrm{mas} / \mathrm{yr}$ are given as derived from a comparison with the Astrographic Catalogue and 143 other ground-based astrometric catalogues, all reduced to the Hipparcos Celestial Reference Frame. Tycho-2 supersedes in most applications Tycho-1, as well as the ACT and TRC catalogues based on Tycho-1.

A study by Makarov et al. (A\&A 358, 923, 2000) of the internal velocity dispersion in the Hyades has confirmed the high quality of the Tycho-2 proper motions. The study shows that the Tycho-2 proper motions have a very similar precision to those of Hipparcos at the same magnitude, but reveal fewer extreme deviants from the common convergent point direction. Tycho-2 proper motions are based on long series of observations, up to 100 years, and are therefore less subject to the orbital motions in binaries. The ratio of the external error to the formal error given in the catalogue may be up to 1.3 for stars fainter than $V_{T}=8.5$ mag.

RESOLUTIONS ON THE "DEFINITION OF RADIAL VELOCITIES" AND ON THE "DESIGNATIONS OF STELLAR COMPANIONS" Summaries were given on the "Resolution on Radial Velocities" by L. Lindegren, and on the "Resolution on the Designations of Stellar Companions" by T. Corbin. For more information reference is made to the reports of Commissions 30 and 5, respectively.

Heiner Schwan

Elena Schilbach

Presidents of the Commissions 
H. Rickman (ed.), Transactions of the International Astronomical Union, Vol. XXIVB, 105-106. (C) 2001 IAU. Printed in the United States of America.

\section{COMMISSION 19: EARTH ROTATION} (ROTATION DE LA TERRE)

PRESIDENT: Dennis McCarthy VICE-PRESIDENT: Nicole Capitaine ORGANIZING COMMTTTEE: F. Arias, G. Beutler, P. Brosche, A. Brzeziński, V. Dehant, M. Feissel, R. Gross, S. Manabe, L. V. Morrison, L. V. Rykhlova, V. K. Tarady, J. Vondrák, C. Wilson, F. Yang, Ya. S. Yatskiv

IAU Commission 19 met on 14 August 2000 at the 24th IAU General Assembly in Manchester, England. The morning sessions were devoted to scientific presentations. The program is given below.

\section{Scientific Meeting}

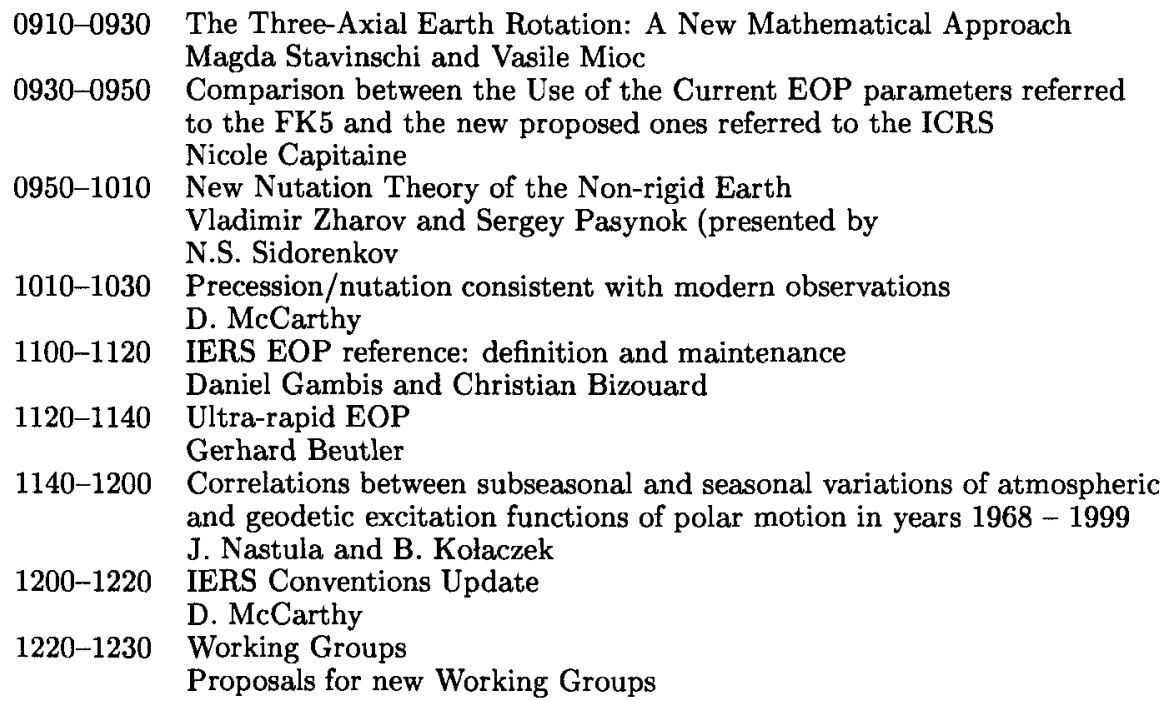

\section{Business Meeting}

The afternoon session was devoted to Commission business. D. Gambis reported on the activities of the International Earth Rotation Service (IERS) during the past three years. This was followed by a short description by D. McCarthy of the new organization of the IERS to be implemented in early 2001 .

The deaths of I. Tsubokawa and Wm. Markowitz were remembered.

New members accepted by the Commission are C. Bizouard, M. De Biasi, W. Dick, J. Ferrandiz, A. M. Gontier, U. Hugentobler, F. Roosbeek, S. Schillak, Z. Zhang, Y. Zhou 
The officers for the coming triennium were elected as follows:
President
N. Capitaine
Vice-President
V. Dehant

Members of the Organizing Committee are listed below

First Term (elected at 24th General Assembly in 2000) T. Fukushima, D. Gambis, J. Hefty, C. Huang, Z. Malkin, A. Poma, J. Ray, C. Ron, N. Sidorenkov, M. Soffel

Second Term (elected at the 23rd General Assembly in 1997) G. Beutler, P. Brosche, A. Brzeziński, R. Gross, Ya. Yatskiv

Past President: D. McCarthy Representative from IERS: B. Richter Representative from IAG: C. Wilson

The Commission consultants for the next three years were accepted as follows: B. Chao, R. Eanes, J. Getino, T. Herring, C. L. Huang, H. Jochman, J. Kouba, O. Kudlay, S. Mathews, J. Nastula, A. Nothnagel, K. Nurutdinov, L. Petrov, C. Reigber, B. Richter, S. Rudenko, D. Salstein, H. Schuh, T. Springer, J. Wahr, R. Weber, C. Wilson, S. Zhu

J. Vondrák was elected to continue as IAU representative to the IERS.

After some discussion, it was agreed that the Commission would form two working groups to serve in the next three years. The topics will be (1) Precession/nutation and (2) High-frequency and Sudden Variations in Earth Orientation. V. Dehant will be asked to serve as the chair of the Precession/nutation Working Group, and M. Rothacher will be asked to serve as chair of the Working Group on High-frequency and Sudden Variations in Earth Orientation.

A letter from A. Gozhy was read. He suggested that the Commission take steps to preserve sites of past astrometric observations for Earth orientation. Members pointed out that a recommendation to that effect was already in consideration by the General Assembly. In view of this pending action, the Commission took no further steps. Gozhy's second suggestion was that the Commission consider a study of the evolution of the Earth's figure. This was discussed, the consensus of the membership being that this was the job of the International Association of Geodesy and not of IAU Commission 19. No further action was taken and the business meeting was closed.

Dennis McCarthy

President of the Commission 
H. Rickman (ed.), Transactions of the International Astronomical Union, Vol. XXIVB, $107-108$. (C)2001 IAU. Printed in the United States of America.

\title{
COMMISSION 31: TIME
}

\author{
(TEMPS)
}

\author{
PRESIDENT: Toshio Fukushima \\ VICE-PRESIDENT: Gérard Petit \\ ORGANIZING COMMITTEE: D.C. Backer, G. Beutler, V.A. Brumberg, \\ H.F. Fliegel, S.M. Leschiutta, J. Luck, P. Paquet, E. Proverbio, G.R. Qi, \\ C. Thomas, C. Veillet, G.M.R. Winkler, Z.C. Zhai
}

\section{Appointment of Officials for 2000-2003}

Drs. G. Petit and D. Matsakis have been elected as the President and Vice President of the Commission for the next term, 2000-2003, respectively. As for the Organizing Committee Members, we welcome D. Matsakis as a new member and appreciate the outgoing members, Drs Brumberg, Fliegel, Luck, Paquet, and Thomas, for their contributions and efforts. Also T. Fukushima was nominated as the IAU Representative to the CIPM/CCTF for the next triennium.

\section{Report of the BIPM Time Section (communicated by F. Arias)}

Reference time scales International Atomic Time (TAI) and Universal Coordinated Time (UTC) have been computed regularly and have been published in the monthly Circular T. Definitive results for 1997,1998 and 1999 have been available, in the form of computerreadable files in the BIPM home-page and on printed volumes of the respective Annual Reports of the BIPM Time Section. The printed version of the last volume has been substantially shortened with the aim to progress to an electronic version in the next future. Work is done to automate the calculation of TAI and UTC, this allowing a shorter delay in the publication of Circular T.

Research concerning time scale algorithms includes studies to improve the long-term stability of the free atomic time scale EAL and the accuracy of TAI. Studies are undertaken to evaluate the feasibility of providing a prediction of UTC in quasi-real time. Some $80 \%$ of the clocks are now either commercial caesium clocks of the type HP5071A or active, auto-tuned active hydrogen masers, and together they contribute $86 \%$ of the total weight with consequent improvement in the stability of EAL. Since most HP5071A clocks have at present the maximum relative weight, the weighting procedure of clocks in TAI is under revision. The medium-term stability of EAL, expressed in terms of the Allan deviation, is estimated to be $0.6 \times 10^{15}$ for averaging times of 20 to 40 days over the period. Nine primary frequency standards reported their measures to the BIPM. The global treatment of these individual measurements led to a relative departure of the duration of the TAI scale unit from the SI second on the geoid ranging, in the last year, from $+0.2 \times 10^{14}$ to $+0.6 \times 10^{14}$, with an uncertainty of $0.4 \times 10^{14}$. Following the recommendations of the Consultative Committee on Time and Frequency, changes were implemented to render the data used in TAI, as well as the results, more accessible to the users and to make the procedures of calculation even more transparent and traceable. Since April 2000 two modifications were implemented: a new model to characterise the instability of the free atomic scale EAL, and a more complete representation of the uncertainty of the deviation of the TAI scale interval relative to that of the Terrestrial Time $\mathrm{TT}$. 
In the last decade the time links computed at the BIPM used the classical GPS common-view technique based on C/A-code measurements obtained from one-channel receivers. The commercial availability of newly developed receivers has stimulated interest in extending the classical common-view technique for use of multichannel dual-code dualsystem (GPS and GLONASS) observations, with the aim of improving the accuracy of time transfer. The two-way time transfer via geostationary satellites (TWSTFT) proved to be potentially better that GPS. Since July 1999 GPS multichannel links and TWSFTF links are being progressively introduced in TAI. In addition, the BIPM Time section carries on testing other time and frequency comparison methods, such as phase measurements. Ionospheric parameters and precise ephemerides provided by the IGS (International GPS Service) are now routinely used to correct all links in regular TAI calculations.

The BIPM/IAU Joint Committee on general relativity for space-time reference systems and metrology (JCR), created in 1997, continued its work. Two studies have been conducted at the BIPM in collaboration with other members of the JCR. One concerns the extension of the relativistic framework to allow a correct treatment for time transformations and the realisation of barycentric coordinate time at the full post Newtonian level. The second study concerns the realisation of geocentric coordinate times. Following a Call for Participation of the IERS, the BIPM, jointly with the USNO, will provide its Conventions Product Centre since January 2001.

\section{Report of USNO Time Service Dept. (communicated by D. Matsakis)}

The U.S. Naval Observatory (USNO) Time Service Department has a real-time mission to keep the USNO Master Clock as stable and as close to UTC as possible, and to disseminate its time via GPS and other means, such as Two-Way Satellite Time Transfer (TWSTT) and Loran. To achieve the required stability and robustness, we maintain a large ensemble of clocks - about 65 HP5071 cesiums and 15 cavity-tuned Datum masers, distributed in three buildings at two sites, kept in environmentally benign conditions, and intercompared using state-of-the-art measurement systems.

Although most of our 28-person staff is involved with maintaining the hardware, software, and data flow needed for our operations, we are also finding ways to improve things. We are about to switch to a more stable and robust measurement system; have recently improved our clock steering algorithms; are testing steering algorithms that are better still; are constructing improved chambers to house our clocks; are developing better GPS receivers; have improved timescale and clock-characterization algorithms; are building atomic fountains; and are purchasing trapped-ion mercury clocks from Lute Maleki's group at Jet Propulsion Laboratory (JPL).

The driver for many of our upgrade plans is the anticipated needs of specific users, among them GPS. But it is also worthy of note that we cannot do it alone. We need the help of the timekeeping community, and we are seeking to improve cooperation in many ways. To help improve the short-term stability of TAI, we are cooperating with the BIPM in making TWSTT the operational mode for TAI generation, and are interested in improving TWSTT technology through carrier-phase receive systems and more stable hardware. Another very exciting mode of time transfer is carrier-phase GPS. Under the leadership of the BIPM and the IGS, we are again working on improvements to both the software and hardware. With Allan Osborne Associates we have found a hardware fix that promises to make their widely used receivers calibratable and robust in a timekeeping sense; with Ron Muellerschoen of JPL we have developed a continuous Kalman filter so that day-boundary processing discontinuities can be avoided; with data from many IGS sites created and published a frequency scale based only on GPS carrier-phase data; and with Joe White and Ron Beard of Naval Research Laboratory (NRL) we are conducting absolute calibration studies on many hardware components.

Toshio Fukushima

President of the Commission 